\title{
Thermal Analysis of Natural Esters in a Low-Voltage Disc-type Winding of a Power Transformer
}

\author{
A. Santisteban, F. O. Fernández, I. Fernández F. Delgado, A Ortiz, C.J. Renedo \\ Department of Electrical and Energy Engineering \\ ETSIIT, University of Cantabria \\ Santander, Spain \\ e-mail: agustin.santisteban@unican.es
}

\begin{abstract}
This work compares the temperature distribution and hot-spot temperatures obtained in a disc-type winding of a power transformer when using as dielectric liquid a mineral oil or natural esters. The comparison is made with a reference case for mass flow rate and temperature in the inlet and uniform losses for the discs. A further comparison is performed by increasing the mass flow rate at the inlet form $0.78 \mathrm{~kg} / \mathrm{s}$ to 0.9 and $1.0 \mathrm{~kg} / \mathrm{s}$, thus nine case studies are considered in this work. These cases have been analyzed via CFD techniques using the software COMSOL Multiphysics ${ }^{\circledR}$ with a 2D-axysymmetrical model using the Conjugate Heat Transfer module. For the analysis, the hotspot factor $H$ is considered as an indicator of the cooling circuit efficiency since the losses are uniform. Results shows that for the base case, the hot-spot temperature obtained for the mineral oil is $9-11^{\circ} \mathrm{C}$ higher than the obtained with esters whereas for the increased mass flow rate, hot-spot temperature of mineral oil is equal or even lower than the obtained for natural esters. The analysis of the hot-spot factor shows the dependence of the cooling circuit efficiency on the kind of oil and inlet conditions.
\end{abstract}

Keywords- CHT, natural ester, hot-spot, power transformer, disc winding.

\section{INTRODUCTION}

Power transformers are one of the main devices in transmission and power supply networks. Although their efficiency is over $99 \%$, the amount of power losses they produce leads to a harmful heating of the device. The highest temperature obtained, also known as hot-spot temperature, is a value that affects directly to the degradation of transformer insulation system and thus the machine lifetime. Due to this, it becomes necessary to add a cooling system inside the transformer. For small distribution transformer it is enough with ambient air but for large power transformers more efficient cooling is needed to ensure their performance. In this case, the most extended coolant is mineral oil. The problems that mineral oil presents are its low flash and ignition point and its low biodegradability. Those facts have encouraged the development of new alternative dielectric liquids that overcome the problems previously announced. This kind of liquids are divided in four groups: high molecular weight hydrocarbons, silicone-based oils, vegetal oils and synthetic esters. All of them have an ignition point over $300^{\circ} \mathrm{C}$, but only the last two types are biodegradable [1]. To determine the cooling capacity of these fluids in a power transformer, a numerical analysis can be carried out. There are two main techniques for this analysis, first is the Thermal-Hydraulic Network Model (THNM) and second is the Computer Fluid Dynamics (CFD).

In the literature, some papers can be found where these techniques are used to predict hot-spots and temperature distributions in oil immersed transformers. In 2000, Mufuta et al. [2] used a commercial CFD software to characterize the oil flow through an array of discs with different spaces between discs and different inlet conditions. Later in 2006, El Wakil et al. [3] employed a 2D axisymmetric model of a power transformer with six different geometries and six different inlet velocities in order to study the oil flow. Rahimpour et al. [4] used in 2007 a Thermal Network Model (TNM) to determine which parameters affect to the hot-spot temperature magnitude in a zigzag cooled transformer winding. In 2008, Zhang et al. [5] created a THNM for an oil immersed transformer winding with zigzag cooling and established empirical correlations to determine the local heat transfer coefficients, developing a thermal model with good agreement with experimental results. Two years later, Torriano et al. [6] performed simulations of a low-voltage winding (LVW) of a power transformer with zigzag cooling in order to determine the accuracy of different 2D axisymmetric models based on coupling CFD and heat transfer. In 2011, Gastelurrutia et al. [7] carried out a study where the developed a 3D and a 2D models of an ONAN (Oil Natural-Air Natural) distribution transformer by using CFD techniques. The simplified $2 \mathrm{D}$ model had a good capacity to represent the thermal behavior of the whole transformer. In 2012, Tsili et al. [8] established a methodology to develop a 3D model to predict hot-spot temperature by coupling fluid flow and heat transfer via Finite Element Method (FEM). They applied the developed method to predict hot-spot temperatures and temperature profiles for two distribution transformers. In this year, Skillen et al. [9] carried out a study of a 2D model for the fluid domain in a non-isothermal axisymmetric simulation in order to characterize the oil flow inside a transformer disc type winding. Also, Torriano et al. [10] performed a 2D axisymmetric and a 3D simulation of a transformer winding with zigzag cooling to determine the effects of elements of the 
transformer, such as sticks and intersticks, in the temperature distribution, that are not considered in 2D model. In 2014, Yatsevsky [11] carried out a 2D axisymmetric simulation of a Conjugate Heat Transfer (CHT) model of a transformer, including the core, the tank and the radiator, in order to predict hot-spots in an oil immersed transformer with natural convection. The developed model has shown a good adequacy verified by experiments. In 2015 Park et al. [12] employed a $2 \mathrm{D}$ model in order to obtain temperature and velocity profiles of some alternative liquids used in a distribution transformer of 2.3 MVA and a power transformer of 16.5 MVA. In the same year, Lecuna et al. [13] carried out a 3D simulation of an ONAN distribution transformer comparing a natural ester, a synthetic ester, a high kinematic viscosity silicone oil and a low kinematic viscosity silicone oil with a mineral oil.

In this work a 2D-axysymmetrical CFD model is used to assess the thermal performance of two different natural esters in a low-voltage winding, considering fluid and active part, of a power transformer when increasing the mass flow rate at the inlet. The results obtained are compared with those obtained with a mineral oil.

\section{MODEL DESCRIPTION}

\section{A. Geometry}

The geometry considered for the study consists of a disctype winding of a power transformer. This winding is formed by 78 discs divided in 4 passes of 19 discs each and separated by a block washer except for the first pass which has 21 discs and an extra washer.

Each pass, shown in Figure 1, has an inner and an outer axial duct of 8.9 and $6.4 \mathrm{~mm}$ width respectively. In each pass, one of the duct acts as a distributing duct and the other acts as a collector duct so the oil pass through 20 horizontal ducts of $4.1 \mathrm{~mm}$ height. The collector and distributor duct swap in each pass so there is a zigzag flow.

Each disc consists of 18 copper conductor which are wrapped with insulation paper of $0.4 \mathrm{~mm}$ thickness each. The whole disc is $15 \mathrm{~mm}$ height and $50.8 \mathrm{~mm}$ width. The inner radius of the winding is $316.2 \mathrm{~mm}$.

\section{B. Governing equations}

The model presented in this work is solved via Conjugate Heat Transfer, which combines heat transfer with fluid flow.

For the fluid domain steady-state incompressible NavierStokes equations need to be satisfied.

$$
\begin{aligned}
& \nabla \cdot(\rho \boldsymbol{u})=0 \\
& \nabla \cdot(\rho \boldsymbol{u} \times \boldsymbol{u})=-\nabla p+\mu(\nabla 2 \boldsymbol{u})+\boldsymbol{g}(\rho-\rho r e f) \\
& \nabla \cdot\left(\rho c_{p} \boldsymbol{u} T\right)=\nabla \cdot(k \cdot \Delta T)+q_{s}
\end{aligned}
$$

Equation (1) refers to the mass conservation, where $\rho$ is the density and $\boldsymbol{u}$ is the velocity field. Equation (2) is the momentum conservation equation, where $p$ is the pressure, $\mu$ is the viscosity and $\boldsymbol{g}$ is the gravity vector. Equation (3) is the energy conservation equation where $c_{p}$ is the specific heat, $T$ is

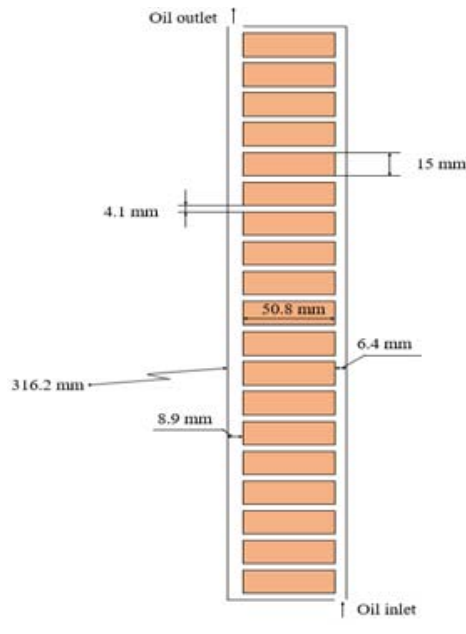

Fig. 1. Geometry of the model.

the temperature, $k$ is the thermal conductivity and $q_{s}$ is the heat source term.

For the solid domain, the steady-state heat conduction equation needs to be solved

$$
0=-\nabla \cdot(k \cdot \Delta T)+q_{s}
$$

Where the source term in (4), refers to the losses in the winding.

\section{Boundary conditions}

For the study proposed, a mass flow rate of $0.78 \mathrm{~kg} / \mathrm{s}$ at a temperature of $46.7^{\circ} \mathrm{C}$ is imposed at the inlet. A uniform heat source of $676.9 \mathrm{~W} / \mathrm{disc}$ is set to represent the heat losses. At the outlet section, a pressure condition $p=0$ is specified. For the bottom part of the first disc, a heat transfer coefficient $h$ of 100 $\mathrm{W} /\left(\mathrm{m}^{2} \bullet \mathrm{K}\right)$ is considered. Exterior boundaries are considered adiabatic since they are covered with materials of low thermal conductivity.

\section{Material properties}

The dielectric liquids considered in this study are two different kind of natural esters and a mineral oil. Thermal properties such as density, specific heat, thermal conductivity and viscosity are presented in Table I. For the solid parts of the

\begin{tabular}{|c|c|c|}
\hline \multirow{3}{*}{$\begin{array}{l}\text { Density } \\
\left(\mathrm{kg} / \mathrm{m}^{3}\right)\end{array}$} & Mineral & $1098.72-0.712 \cdot \mathrm{T}$ \\
\hline & Ester 01 & $1109.2-0.653 \cdot \mathrm{T}$ \\
\hline & Ester 02 & $1108-0.666 \cdot \mathrm{T}$ \\
\hline \multirow{3}{*}{$\begin{array}{c}\text { Specific heat } \\
(\mathrm{J} / \mathrm{kg} \cdot \mathrm{K})\end{array}$} & Mineral & $807.163+3.57 \cdot \mathrm{T}$ \\
\hline & Ester 01 & $1273.15+1.952 \cdot \mathrm{T}$ \\
\hline & Ester 02 & $1902.1+2.98 \cdot \mathrm{T}$ \\
\hline \multirow{3}{*}{$\begin{array}{l}\text { Conductivity } \\
(\mathrm{W} / \mathrm{m} \cdot \mathrm{K})\end{array}$} & Mineral & $0.1509-7.101 \mathrm{e}-05 \cdot \mathrm{T}$ \\
\hline & Ester 01 & $0.1317+4.142 \mathrm{e}-04 \cdot \mathrm{T}-8.86 \mathrm{e}-07 \cdot \mathrm{T}^{2}$ \\
\hline & Ester 02 & $0.1979-9.564 \mathrm{e}-5 \cdot \mathrm{T}$ \\
\hline \multirow{3}{*}{$\begin{array}{c}\text { Viscosity } \\
(\mathrm{Pa} \cdot \mathrm{s})\end{array}$} & Mineral & $0.08467-4 \mathrm{e}-04 \cdot \mathrm{T}+5 \mathrm{e}-07 \cdot \mathrm{T}^{2}$ \\
\hline & Ester 01 & $7.99-0.0664 \cdot \mathrm{T}+1.84 \mathrm{e}-04 \cdot \mathrm{T}^{2}-1.71 \mathrm{e}-07 \cdot \mathrm{T}^{3}$ \\
\hline & Ester 02 & $1.365-7.41 \mathrm{e}-03 \cdot \mathrm{T}+1.01 \mathrm{e}-05 \cdot \mathrm{T}^{2}$ \\
\hline
\end{tabular}
windings, copper and insulation paper are considered for the discs. Table II shows properties for copper and paper.

TABLE I. PHYSICAL PROPERTIES OF MINERAL OIL AND ESTERS 


\section{E. Meshing}

The model is solved with the commercial CFD software COMSOL Multiphysics ${ }^{\circledR}$ using the CHT module. To reduce computational requirements only one pass is considered for each simulation and velocity and temperature profiles obtained in the outlet section are imposed for the inlet section of the next pass, following the methodology in [10].

For the whole pass, a structured quadrilateral mesh is built, with a maximum size of $0.1 \mathrm{~mm}$ per side. The whole pass consists of over 2,500,000 elements. Results of the model have been validated with the results presented by [6], obtaining a maximum discrepancy on the average disc temperature of less than $1^{\circ} \mathrm{C}$. Simulations took between 8 and 10 hours per case.

\section{RESULTS AND DISCUSSION}

In this work, two different natural esters are compared to a mineral oil. To assess the thermal performance, the same mass flow rate is considered to compare the thermal properties of each liquid. For this study, different mass flow rates are considered at the inlet: a reference mass flow rate of $0.78 \mathrm{~kg} / \mathrm{s}$ and an increased mass flow rate of 0.9 and $1.0 \mathrm{~kg} / \mathrm{s}$.

\section{A. Base case}

In this case three different liquids are studied under the conditions described in [6]. For the base case, mineral oil produces higher temperatures on the discs than natural esters as can be seen in the Figure 2. The hot-spot temperature obtained for mineral oil is between $9-11^{\circ} \mathrm{C}$ higher than the one obtained for natural esters in this case.

\section{B. Rest of the cases}

Other cases have been analyzed when increasing the mass flow rate at the inlet. As expected, lower temperatures are obtained for all liquids when increasing the inlet rate but the reduction of temperature is much higher for mineral oil than for natural esters. For example, the hot-spot temperature obtained for the mineral oil for the base case is $114.7^{\circ} \mathrm{C}$ and for the 0.9 $\mathrm{kg} / \mathrm{s}$ inlet case is $101.1^{\circ} \mathrm{C}$ whereas for one ester is $103.5^{\circ} \mathrm{C}$ for the base case and $100.8^{\circ} \mathrm{C}$ for the $0.9 \mathrm{~kg} / \mathrm{s}$ inlet case. This could be expected if it is considered the lower viscosity of the mineral oil, which becomes important when the inertia forces increases. Table III shows the values of hot-spot temperature, $T_{h s}$, average winding temperature, $T_{w}$, and top oil temperature, $T_{o}$, for all cases studied.

\section{Hot-spot factor}

A parameter considered for the study is the hot-spot factor, $H$, which is defined in [14] as "a dimensionless factor to estimate the local increase of the winding gradient due to the

TABLE II. PHYSICAL PROPERTIES OF SOLID MATERIALS

\begin{tabular}{|c|c|c|}
\hline \multirow{2}{*}{ Density $\left(\mathrm{kg} / \mathrm{m}^{3}\right)$} & Copper & 8933 \\
\cline { 2 - 3 } & Paper & 930 \\
\hline \multirow{2}{*}{ Specific heat $(\mathrm{J} / \mathrm{kg} \cdot \mathrm{K})$} & Copper & 385 \\
\cline { 2 - 3 } & Paper & 1340 \\
\hline \multirow{2}{*}{ Conductivity $(\mathrm{W} / \mathrm{m} \cdot \mathrm{K})$} & Copper & 401 \\
\cline { 2 - 3 } & Paper & 0.19 \\
\hline
\end{tabular}

increase of additional loss and variation in the liquid flow stream." This factor is a product of two factors, $Q$ and $S$. The $Q$ factor represents the ratio of the local losses between the average losses. For this study since uniform heat source is considered, the value of the $Q$ factor is 1 for all cases. The $\mathrm{S}$ factor represents the non-uniform cooling inside the transformer.

Since the hot-spot temperature is defined as follows:

$$
\mathrm{T}_{\mathrm{hs}}=\mathrm{T}_{\mathrm{o}}+\mathrm{H} \cdot \mathrm{g}_{\mathrm{r}}
$$

Where $g_{r}$ represents the winding gradient. The hot-spot factor can be calculated with the following equation:

$$
\mathrm{H}=\left(\mathrm{T}_{\mathrm{hs}}-\mathrm{T}_{\mathrm{o}}\right) /\left(\mathrm{T}_{\mathrm{w}}-\mathrm{T}_{\text {oil }}\right)
$$

Where the difference $T_{w}-T_{\text {oil }}$ represents the winding gradient and $T_{\text {oil }}$ is the average oil temperature that is calculated as the average of the top and bottom oil temperature.

All values are obtained from simulations and the hot-spot factor of all cases are represented in Table IV. It can be seen that the hot-spot factor depends on the kind of liquid and on the inlet rate.

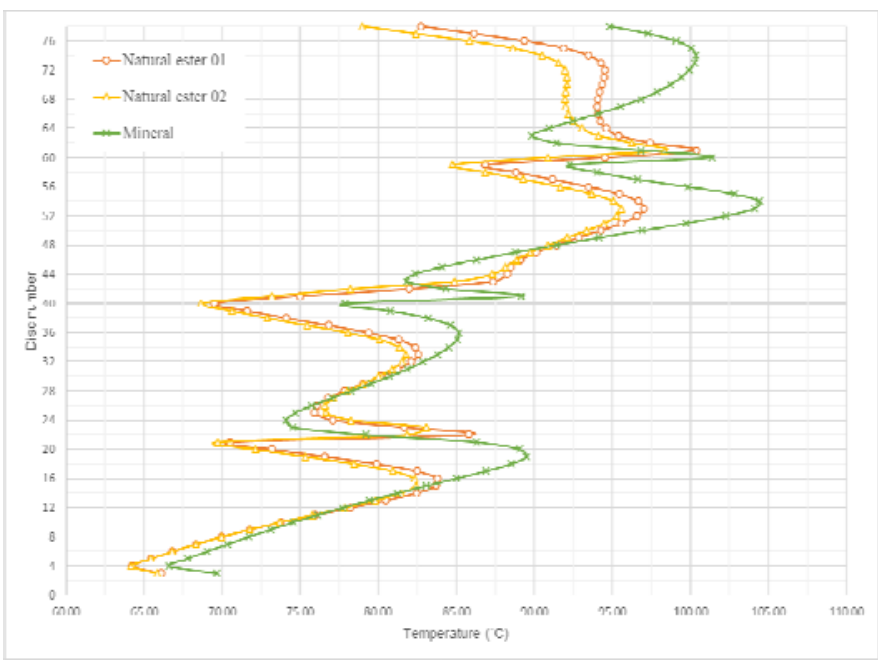

Fig. 2. Temperature profiles.

TABLE III. TEMPERATURE VALUES

\begin{tabular}{|c|l|c|c|c|}
\hline \multicolumn{2}{|c|}{} & $\boldsymbol{T}_{\boldsymbol{o}}$ & $\boldsymbol{T}_{\boldsymbol{w}}$ & $\boldsymbol{T}_{\boldsymbol{h s}}$ \\
\hline \multirow{4}{*}{ Base case } & Mineral & 79.5 & 86.7 & 114.7 \\
\cline { 2 - 5 } & Ester 01 & 80.7 & 83.8 & 105.3 \\
\cline { 2 - 5 } & Ester 02 & 78.0 & 82.6 & 103.5 \\
\hline \multirow{3}{*}{$0.9 \mathrm{~kg} / \mathrm{s}$} & Mineral & 75.1 & 83.1 & 101.1 \\
\cline { 2 - 5 } & Ester 01 & 76.1 & 81.7 & 102.1 \\
\cline { 2 - 5 } & Ester 02 & 73.8 & 80.8 & 100.8 \\
\hline \multirow{3}{*}{$1 \mathrm{~kg} / \mathrm{s}$} & Mineral oil & 72.1 & 81.4 & 97.6 \\
\cline { 2 - 5 } & Ester 01 & 73.2 & 80.5 & 100.8 \\
\cline { 2 - 5 } & Ester 02 & 71.1 & 79.7 & 99.3 \\
\hline
\end{tabular}


TABLE IV. HOT-SPOT FACTOR VALUES

\begin{tabular}{|c|c|c|c|}
\hline \multicolumn{2}{|c|}{} & Hot-spot location & $\boldsymbol{H}$ \\
\hline \multirow{3}{*}{ Base case } & Mineral & Disc 54 & 1.49 \\
\cline { 2 - 4 } & Ester 01 & Disc 53 & 1.22 \\
\cline { 2 - 4 } & Ester 02 & Disc 53 & 1.26 \\
\hline \multirow{3}{*}{$0.9 \mathrm{~kg} / \mathrm{s}$} & Mineral & Disc 54 & 1.17 \\
\cline { 2 - 4 } & Ester 01 & Disc 62 & 1.28 \\
\cline { 2 - 4 } & Ester 02 & Disc 52 & 1.31 \\
\hline \multirow{3}{*}{$1 \mathrm{~s} / \mathrm{s}$} & Mineral & Disc 70 & 1.16 \\
\cline { 2 - 4 } & Ester 01 & Disc 63 & 1.34 \\
\cline { 2 - 4 } & Ester 02 & Disc 52 & 1.36 \\
\hline
\end{tabular}

\section{CONCLUSIONS}

In this work, three different dielectric liquids has been analyzed at three different inlet rates in order to compare their thermal-hydraulic behavior. With the lowest inlet rate, it is observed that natural ester cooling leads to a lower hot-spot temperature whereas for the highest inlet rate the lowest hotspot temperature is observed for mineral oil.

Regarding the hot-spot factor results, the variability of the non-uniform cooling parameter supposed difficulties for the design of the cooling circuit since it depends on the circuit dimensions and kind of fluid and its inlet rate. That means that a good design for an existing liquid e.g. mineral oil might not be a good design for an alternative liquid such as natural ester.

\section{ACKNOWLEDGMENT}

The research leading to these results has received funding from multiple sources over years, but we would specifically like to acknowledge the support received in the later stages from the Spanish Plan Estatal de $\mathrm{I}+\mathrm{D}$ under the grant agreement DPI2015-71219-C2-1-R. Also A.Santisteban would like to thank the University of Cantabria and the Government of Cantabria for the supporting of his Ph.D. scholarship.

\section{REFERENCES}

[1] I. Fernández, A. Ortiz, F. Delgado, C. Renedo, and S. Pérez, "Comparative evaluation of alternative fluids for power transformers," Electr. Power Syst. Res., vol. 98, pp. 58-69, 2013.

[2] J. M. Mufuta and E. Van Den Bulck, "Modelling of the mixed convection in the windings of a disc-type power transformer," Appl. Therm. Eng., vol. 20, no. 5, pp. 417-437, 2000.

[3] N. El Wakil, N.-C. Chereches, and J. Padet, "Numerical study of heat transfer and fluid flow in a power transformer," Int. J. Therm. Sci., vol. 45, no. 6, pp. 615-626, Jun. 2006.

[4] E. Rahimpour, M. Barati, and M. Schäfer, "An investigation of parameters affecting the temperature rise in windings with zigzag cooling flow path,” Appl. Therm. Eng., vol. 27, no. 11-12, pp. 1923$1930,2007$.

[5] J. Zhang, X. Li, and M. Vance, "Experiments and modeling of heat transfer in oil transformer winding with zigzag cooling ducts," Appl. Therm. Eng., vol. 28, no. 1, pp. 36-48, 2008.

[6] F. Torriano, M. Chaaban, and P. Picher, "Numerical study of parameters affecting the temperature distribution in a disc-type transformer winding," Appl. Therm. Eng., vol. 30, no. 14-15, pp. 2034-2044, Oct. 2010 .

[7] J. Gastelurrutia, J. C. Ramos, G. S. Larraona, A. Rivas, J. Izagirre, and L. Del Río, "Numerical modelling of natural convection of oil inside distribution transformers," Appl. Therm. Eng., vol. 31, no. 4, pp. 493505, 2011.

[8] M. A. Tsili, E. I. Amoiralis, A. G. Kladas, and A. T. Souflaris, "Power transformer thermal analysis by using an advanced coupled $3 \mathrm{D}$ heat transfer and fluid flow FEM model," Int. J. Therm. Sci., vol. 53, pp. 188-201, 2012.

[9] A. Skillen, A. Revell, H. Iacovides, and W. Wu, "Numerical prediction of local hot-spot phenomena in transformer windings," Appl. Therm. Eng., vol. 36, no. 1, pp. 96-105, 2012.

[10] F. Torriano, P. Picher, and M. Chaaban, "Numerical investigation of 3D flow and thermal effects in a disc-type transformer winding," Appl. Therm. Eng., vol. 40, pp. 121-131, 2012.

[11] V. A. Yatsevsky, "Hydrodynamics and heat transfer in cooling channels of oil-filled power transformers with multicoil windings," Appl. Therm. Eng., vol. 63, no. 1, pp. 347-353, 2014.

[12] T.-W. Park and S. H. Han, "Numerical analysis of local hot-spot temperatures in transformer windings by using alternative dielectric fluids," Electr. Eng., vol. 97, no. 4, pp. 261-268, 2015.

[13] R. Lecuna, F. Delgado, A. Ortiz, P. B. Castro, I. Fernandez, and C. J. Renedo, "Thermal-fluid characterization of alternative liquids of power transformers: A numerical approach," IEEE Trans. Dielectr. Electr. Insul., vol. 22, no. 5, pp. 2522-2529, 2015.

[14] IEC 60076-2, "Power transformers - Part 2: Temperature rise for liquidimmersed transformers." 2011. 